\title{
Performance Improving of a Concentrating Photovoltaic System by Using a New Optical Adhesive
}

\author{
Intissar Benrhouma1, Nabil Ben Hafsia' ${ }^{1}$, Bechir Chaouachi'1, Marta Victoria ${ }^{2}$, Ignacio Anton ${ }^{2}$ \\ ${ }^{1}$ Energy, Water, Environment and Process Analysis Laboratory, National Engineering School of Gabes, University of Gabes, \\ Gabes, Tunisia \\ ${ }^{2}$ Instituto de Energía Solar, Universidad Politécnica de Madrid, Ciudad Universitaría, Madrid, Spain \\ Email: intissar19913@yahoo.fr
}

How to cite this paper: Benrhouma, I., Hafsia, N.B., Chaouachi, B., Victoria, M. and Anton, I. (2021) Performance Improving of a Concentrating Photovoltaic System by Using a New Optical Adhesive. Journal of Modern Physics, 12, 1607-1617.

https://doi.org/10.4236/jmp.2021.1212095

Received: September 4, 2021

Accepted: October 8, 2021

Published: October 11, 2021

Copyright (c) 2021 by author(s) and Scientific Research Publishing Inc. This work is licensed under the Creative Commons Attribution International License (CC BY 4.0).

http://creativecommons.org/licenses/by/4.0/

\begin{abstract}
The objective of this present study is to manufacture a new silicone-based adhesive which is used for gluing and bonding the second optical elements (SOE) with Concentrating Photovoltaic solar cell (CPV) in order to guarantee a thickness that can provide a good silicone adherence to obtain long term stability and keeping a good solar transmittance performance, too. This new adhesive is made up of a mixture of silicone and transparent glass balls. The experimental part consists of the choice of the best size of glass balls with the suitable proportion of the glass balls weight in the mixture. For this purpose, ten samples were manufactured for every category of glass balls and weight ratio. Glass ball sizes between 100 and $1100 \mu \mathrm{m}$, and weight ratios between 1 and $10 \%$ were analyzed. For each category of glass balls, four proportions were mixed with the silicone. The thicknesses and transmittance of every sample were measured with appropriate instruments. The experimental results illustrate that the mixture containing balls with sizes inferior to $106 \mu \mathrm{m}$, is the best mixture which assures adhesive minimum thickness value necessary for an efficient mechanical bond and preserves also a good transmittance of solar irradiance.
\end{abstract}

\section{Keywords}

Secondary Optical Elements (SOE), Concentrating Photovoltaic Solar Cell (CPV), New Adhesive, Thickness, Transmittance

\section{Introduction}

Today, concentrator photovoltaic systems (CPV) are used to increase the im- 
proving performance of photovoltaic systems (PV) using reflective material lenses, or mirrors to concentrate sunlight on highly efficient solar cells [1]. CPV systems convert solar energy to electric energy by concentrating the incident solar radiation on high efficiency multi-junction (MJ) solar cells. A typical CPV system consists of a solar concentrator, MJ solar cells and a sun tracking system [2].

A concentrated photovoltaic system CPV is composed of a Primary Optical Element POE, a Secondary Optical Element SOE and a solar cell. The role of $\mathrm{POE}$ is to concentrate a large area of solar energy into a small solar cell. Furthermore, the SOE is applied to redirect the sun light into the solar cell and to distribute the energy uniformly on the solar cell [3] [4].

Using only a POE in a photovoltaic system, no-uniformity of the concentrated distribution on the solar cell surface is observed, resulting in localized hot spot or even damage of the solar cell [5] [6]. Localized hot spots and poor uniformity will reduce efficiency of the photovoltaic system and service life of the solar cell. Keeping the power production of a photovoltaic system in real operation conditions under influences of wind and vibration is important. Therefore, precise orientation to the sun of the photovoltaic system is required. One of the ways for lowering the effect of the inaccurate orientation on the concentrator system power efficiency and for improving the irradiation uniformity on the solar cell surface is the application of the SOE located before the solar cell [5] [7].

Secondary optical elements are specular or refracting optical elements of various forms. The parameters of SOE used in a CPV unit are usually tailored according to the design parameters of the POE, performance requirements and the size of the solar cell [5]. Using a SOE will achieve high optical efficiency, lower the sensitivity to the sun tracking error, and improve the uniformity of irradiance distribution on a solar cell [7].

Therefore, the SOEs are different from one to the other. The comparison allows us to interpret that each one of SOE has its acceptance angle, its concentration level and its irradiation. Without using SOE, the optical efficiency reaches a value of $80 \%$ but with using it, the optical efficiency is enhanced. So, for rising concentration, increasing the acceptance angle and/or equalizing irradiance over the cell, the using of a Secondary Optical Element is necessary [7]. Refractive SOE shows a better performance (for the same concentration, they show a wider acceptance angle), than reflective SOE.

When using SOE in the CPV module we should think about the gluing between the SOE and the solar cell. In fact, silicone or polymer can be manufactured by gluing the SOE with a transparent adhesive onto the solar cell. The adhesive can be a sticky silicone or another transparent polymer. Only a thin layer of adhesive is required that presents an advantage since polymers are the most critical material regarding long term stability [8].

The optical characteristic of a CPV system is very affected by the state of the SOE. Hence, a highly gluing between POE and SOE influences also the optical performance. Maike Wiesenfarth et al. manufactured glass-silicone-glass 
samples to measure the transmission and investigated the silicone-solar cell interface and silicone-glass interface to identify possible delaminating. Also possible delaminating of the solar cell silicone was investigated by glass-siliconeprocessed wafer samples and characterized visually. The mechanical stability was investigated with glass cylinders of the same diameter while the optical elements are glued to solar cells. Then, the samples were tested with the substrates held in vertical position in the climate chambers. The complete assemblage is tested with glass-silicone-solar cell samples and characterized before and after testing [8].

A thin layer of silicone is chosen but any increase or decrease in its thickness will affect negatively on the solar cell. With an increasing thickness, the optical efficiency will be lower because it doesn't allow the totality of the irradiance transmission, so a reduction of the PV efficiency. In the other hand, the use of a decreasing thickness could damage the solar cell by the direct contact with the SOE. This direct contact is affected by the silicone loss caused by the temperature increase. The silicone is acting both as an optical coupler to reduce Fresnel losses and as a mechanical bond. To act as mechanical bond it is necessary to use a minimum thickness of silicone. Our objective is to manufacture a mixture between silicone and glass balls to obtain long term stability. The choice of glass balls is due to its optical characteristic; in fact it minimizes the reflection and increasing transmission.

In this work a manufacturing of a new adhesive was investigated. This new adhesive is a mixture of the silicone with the glass balls in order to remain silicone coherent. Several samples were made for different category of glass balls, for each category there were a four percentages that had been studied.

The aim of the present work is to identify a new method to glue the Secondary Optical Element (SOE) to the solar cell and ensure the adequate thickness. The function of using a SOE with a Fresnel lens in a CPV unit is to achieve high optical efficiency, low sensitivity to the sun tracking errors, and improve uniformity of irradiance distribution on the solar cell.

\section{Schema of the Studied System}

As shown in Figure 1, the studied CPV module is composed of the following elements:

- Lens,

- Second optical element,

- Adhesive, that's the layer on which we are going to do the experimental part,

- Solar cell.

\section{Experimental Method}

The objective of the experimental part is to choose the best size of glass balls, with the suitable proportions of the weight of glass balls compared to that of silicone, from five different types of glass balls (Table 1 and Figure 2). 


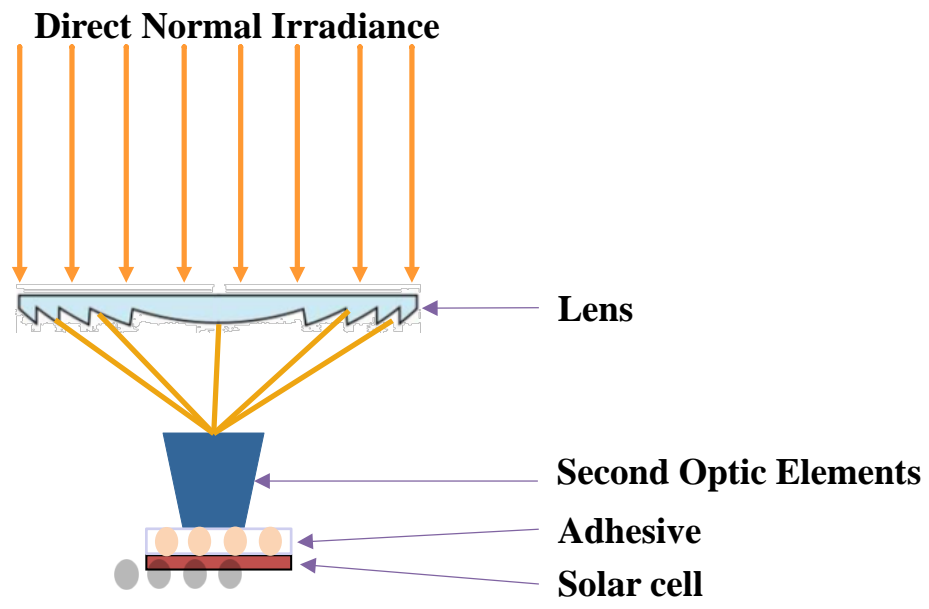

Figure 1. Schema of the studied system.

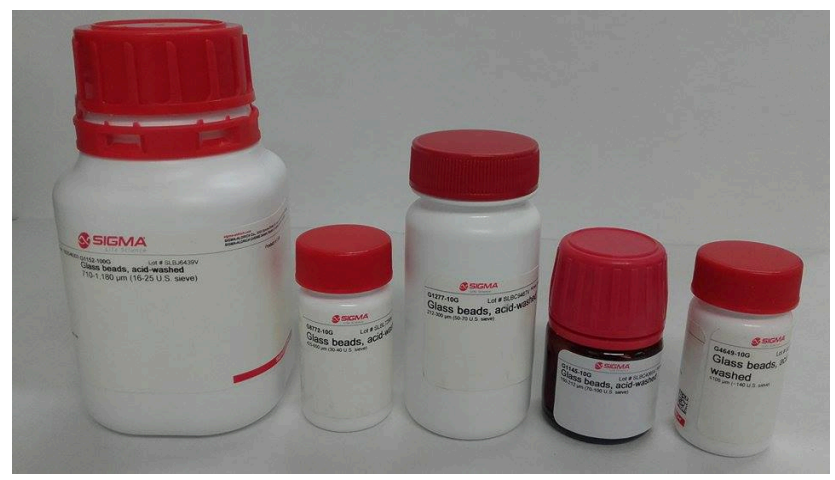

Figure 2. Different sizes of glass balls using in experience.

Table 1. Different sizes of glass balls using in experience.

\begin{tabular}{cc}
\hline Category & Size \\
\hline A & $<106 \mu \mathrm{m}$ \\
B & $150-212 \mu \mathrm{m}$ \\
C & $212-300 \mu \mathrm{m}$ \\
D & $425-600 \mu \mathrm{m}$ \\
E & $710-1180 \mu \mathrm{m}$
\end{tabular}

The proportions of the weight of glass balls compared to that of silicone presented on Table 2 .

For all the samples, $2 \mathrm{~g}$ of silicone elastomer are mixed with $0.2 \mathrm{~g}$ of curing agent to obtain a more coherent silicone. For each type of glass balls, four proportions were mixed with the silicone which was already mixing. $2 \mathrm{~g}$ of silicone gives for each type $0.02 \mathrm{~g}, 0.04 \mathrm{~g}, 0.1 \mathrm{~g}$ and $0.2 \mathrm{~g}$ of glass balls.

After mixing, a drop of the resulting mixture is placed between two flat glasses until this mixture finishes. The mixture is done from 4 to 10 samples for each test. First, vacuum is applied to extract air bubbles from the silicone (Figure 3). The silicone is cured in an oven ( 20 minutes) or at room temperature (48 hours). 
Table 2. The weight of glass balls proportions compared to that of silicone.

\begin{tabular}{cc}
\hline Proportion & Glass ball weight/silicone weight \\
\hline 1 & $1 \%$ \\
2 & $2 \%$ \\
5 & $5 \%$ \\
10 & $10 \%$ \\
\hline
\end{tabular}

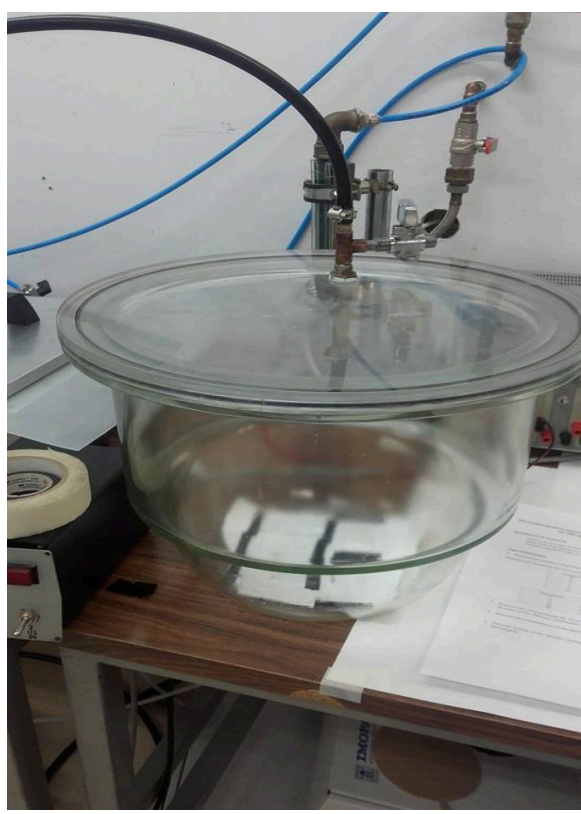

Figure 3. Vacuum for extracting air bubbles.

The different samples thickness measurements is done with the VERNIER as shown in Figure 4 which is a graduated scale placed on the sliding feet, for length and angle measurement. It improves the lecture of the analogical accuracy.

\section{- Transmittance measurement}

Optical measurements were performed using a visible-near-infrared spectroradiometer (VIS-NIR-1 SPECTRO 320 from Instruments Systems). Instrument measurement accuracy is $\pm 3 \%$ and reproducibility is $\pm 0.3 \%$ STD. All the optical measurements were performed two times. Transmittances were measured from 250 to $1000 \mathrm{~nm}$. The samples were almost placed in their right position during the UV irradiance exposure and to perform the optical measurements [9].

\section{- Absorptivity measurement}

Based on the Beer-Lambert law, the optical transmittance of samples $\tau(\lambda)$, is related to its absorption coefficient $\alpha(\lambda)$ and to its optical path-length $x$ as [10]:

$$
\tau(\lambda)=\exp (-\alpha(\lambda) \cdot x)
$$

where $\lambda$ is the wave length. However, the measured transmittance $\tau(\lambda)$ using the spectrophotometer is the total value of the sample layer. Therefore, with only 


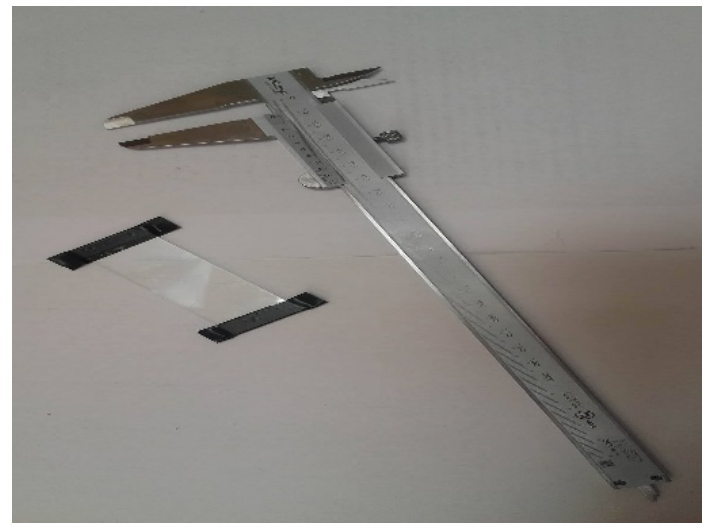

Figure 4. Example of samples with the VERNIER.

silicon samples as the reference, if we obtain two measured transmittance $\tau_{i}(\lambda)$ (transmittance of samples with different sizes glass balls) and $\tau_{\text {ref }}(\lambda)$ (transmittance of samples with only silicon) at two different optical path-lengths $x_{i}$ corresponding to different sizes glass balls and $x_{\text {ref }}$ corresponding to silicon only, the absorption coefficient of the samples $\alpha_{i}(\lambda)$ can be determined from [10]:

$$
\alpha_{i}(\lambda)=\left[-1 /\left(x_{i}-x_{\text {ref }}\right)\right] \ln \left[\tau_{i}(\lambda) / \tau_{\text {ref }}(\lambda)\right]=[-1 / \Delta x] \ln \left[\tau_{i}(\lambda) / \tau_{\text {ref }}(\lambda)\right]
$$

\section{Results and Discussions}

\section{- Thickness measurements mm}

Figure 5 summarizes thicknesses measured for the different samples. The thickness averages for $\mathrm{A}, \mathrm{B}$ and $\mathrm{C}$ categories are almost equal, for different glass balls' percentage values. Besides, these categories are characterized by a low dispersion (dispersion between glass balls), except $\mathrm{C}$ where error is large. For the categories $\mathrm{D}$ and $\mathrm{E}$ the average values are not the same and their dispersions are large, but we note that for $\mathrm{E}$, error is decreased when the percentage becomes $10 \%$.

Figure 6 shows that the categories A and B which characterized by the smallest balls have the lowest dispersion. Dispersion for $\mathrm{C}$ and $\mathrm{D}$ categories is higher independently of percentage value. The $\mathrm{E}$ category has a higher dispersion but we note also a dispersion decrease when the ratio increases. So, the A and B categories have the best measurement results.

\section{- Transmittance measurements}

Figure 7(a) and Figure 7(b) shows the transmittance values corresponding to $5 \%$ and $10 \%$ of categories A, B, C, D and E. For the same percentage (5\% or $10 \%)$ the transmittance values of all categories are around $90 \%$. Figure 8 also shows that the transmittance remains practically the same when the percentage of glass balls is varied (case of category A).

Figure 9 shows that the transmittance of the samples with glass balls (A) is almost similar to the transmittance of sample with silicone only. The difference between them is very small, and it is only from 290 to $360 \mathrm{~nm}$ as shown in Figure 10. The difference between glass balls and silicone is not important because for those wavelengths the irradiance value is low. 


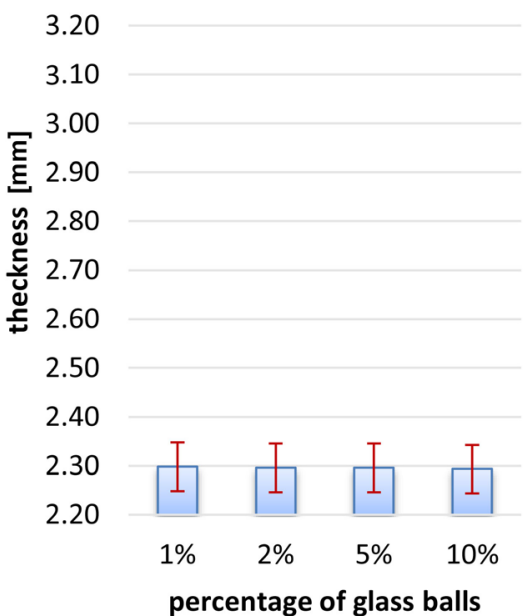

(a)

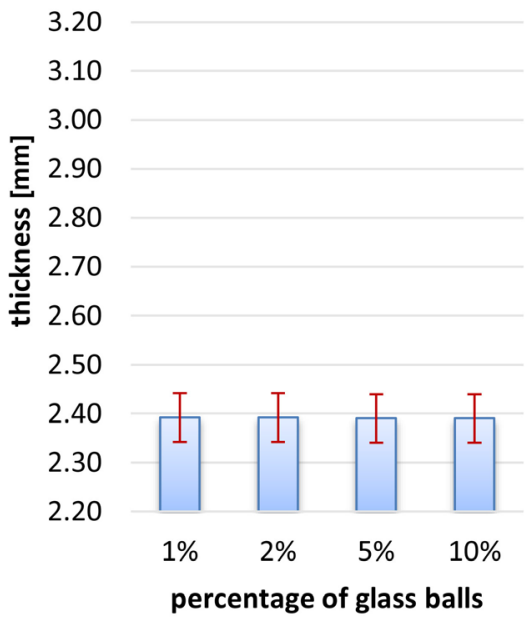

(b)

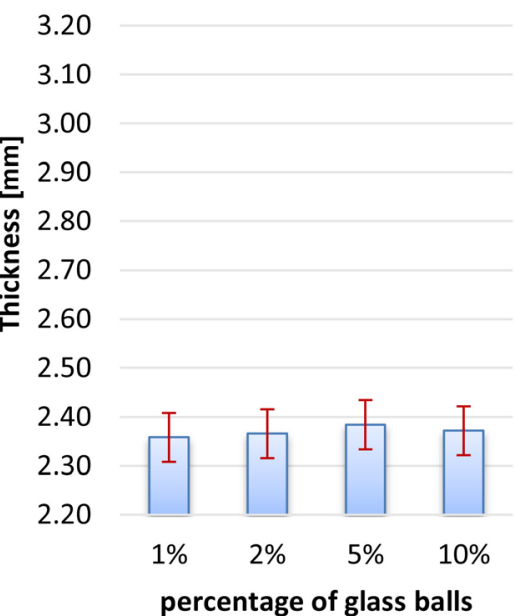

(c)

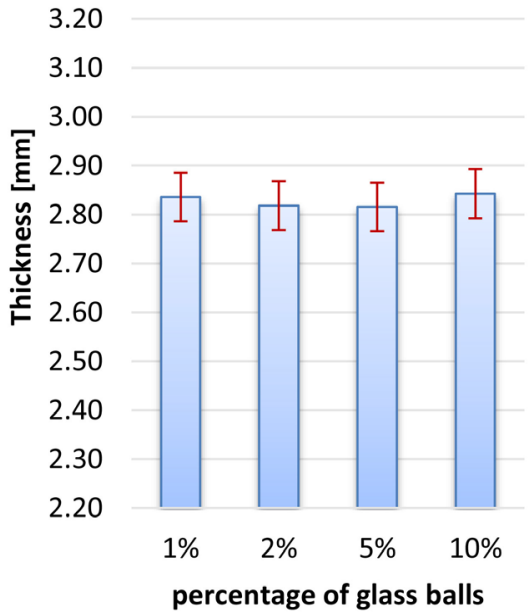

(d) 3.4

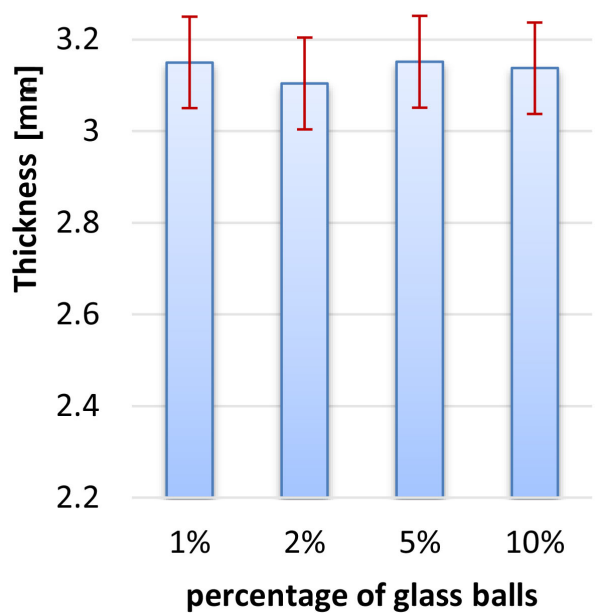

(e)

Figure 5. Dimensions with error bars for different categories; (a) A with 1\%, 2\%, 5\% and $10 \%$ of glass balls; (b) B with $1 \%, 2 \%, 5 \%$ and $10 \%$ of glass balls; (c) C with $1 \%, 2 \%, 5 \%$ and $10 \%$ of glass balls; (d) D with $1 \%, 2 \%, 5 \%$ and $10 \%$ of glass balls. 


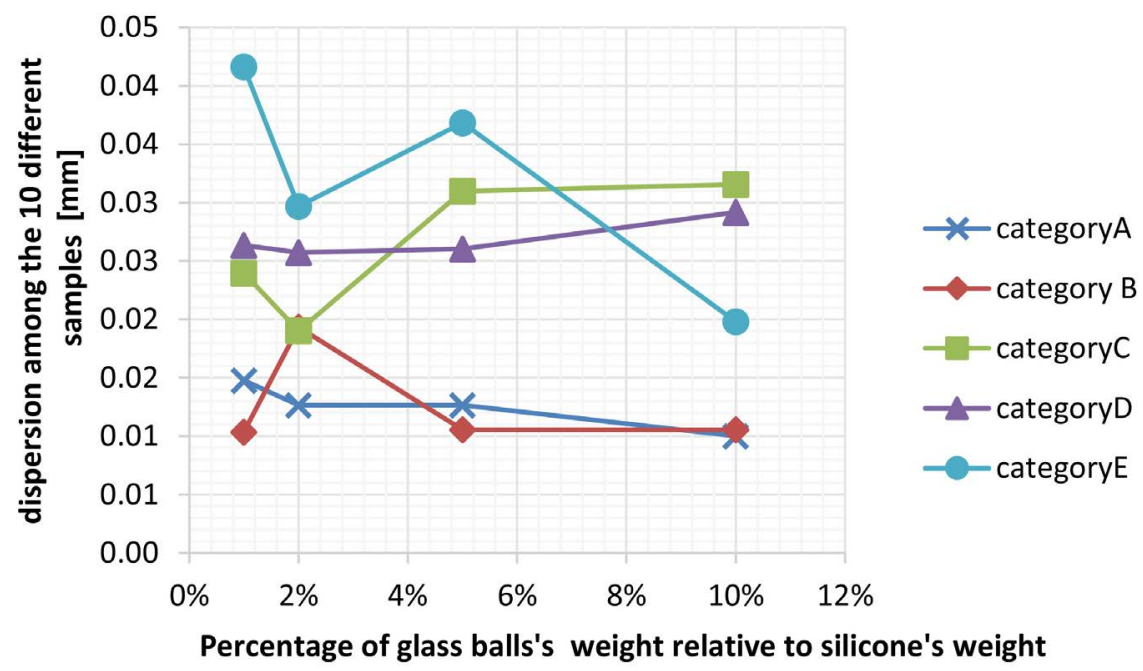

Figure 6. Dispersions for different categories of glass balls.

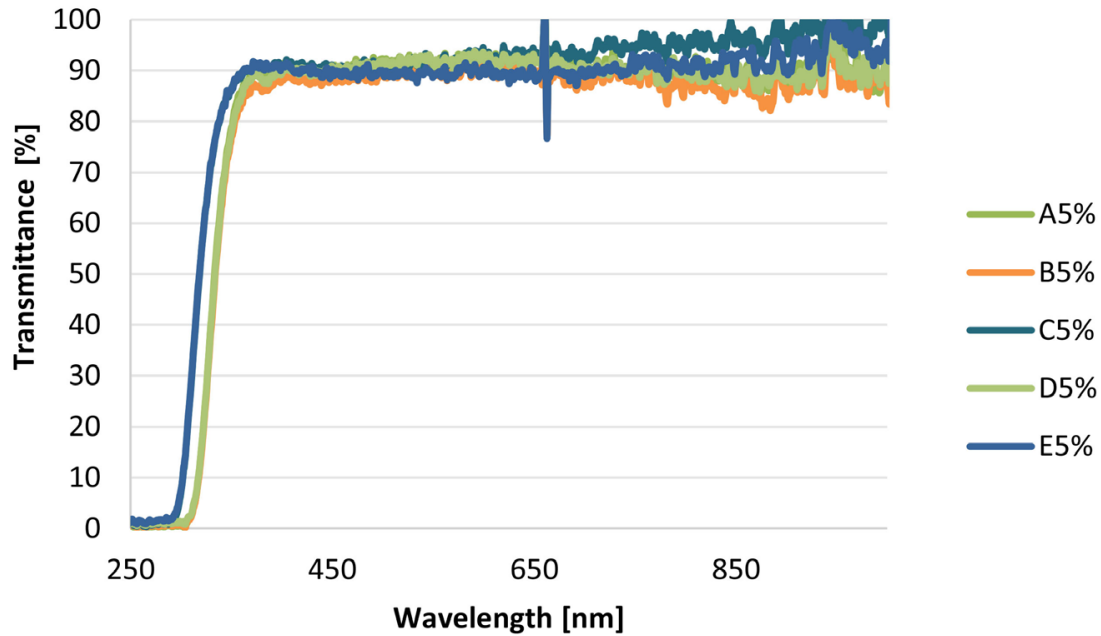

(a)

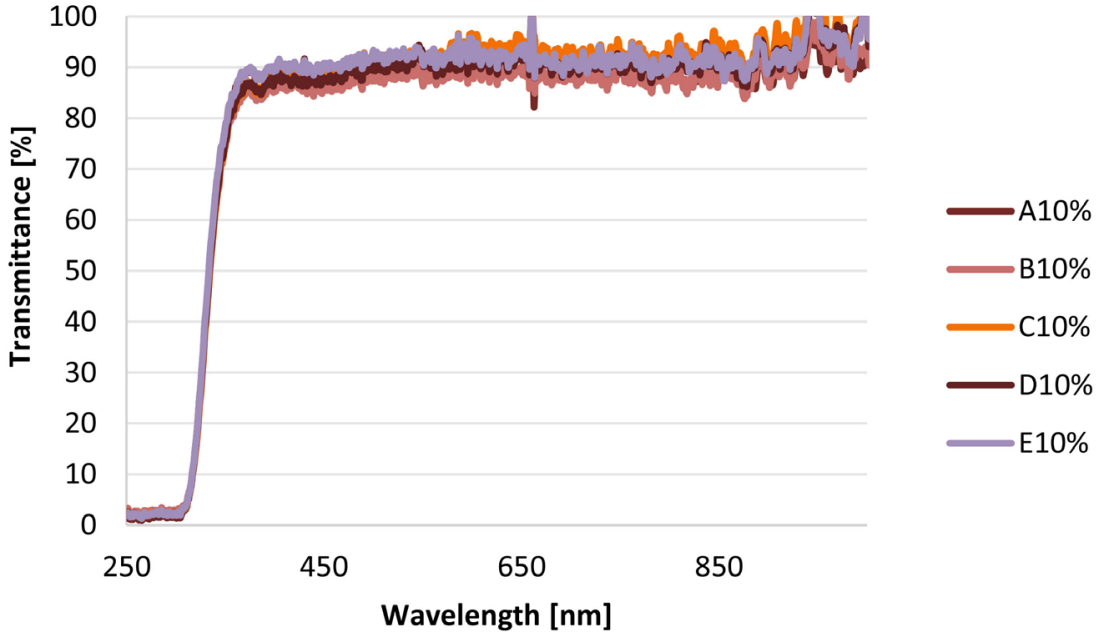

(b)

Figure 7. (a) Transmittance corresponding to $5 \%$ of categories A, B, C, D and E, (b) Transmittance corresponding to $10 \%$ of categories A, B, C, D and E. 


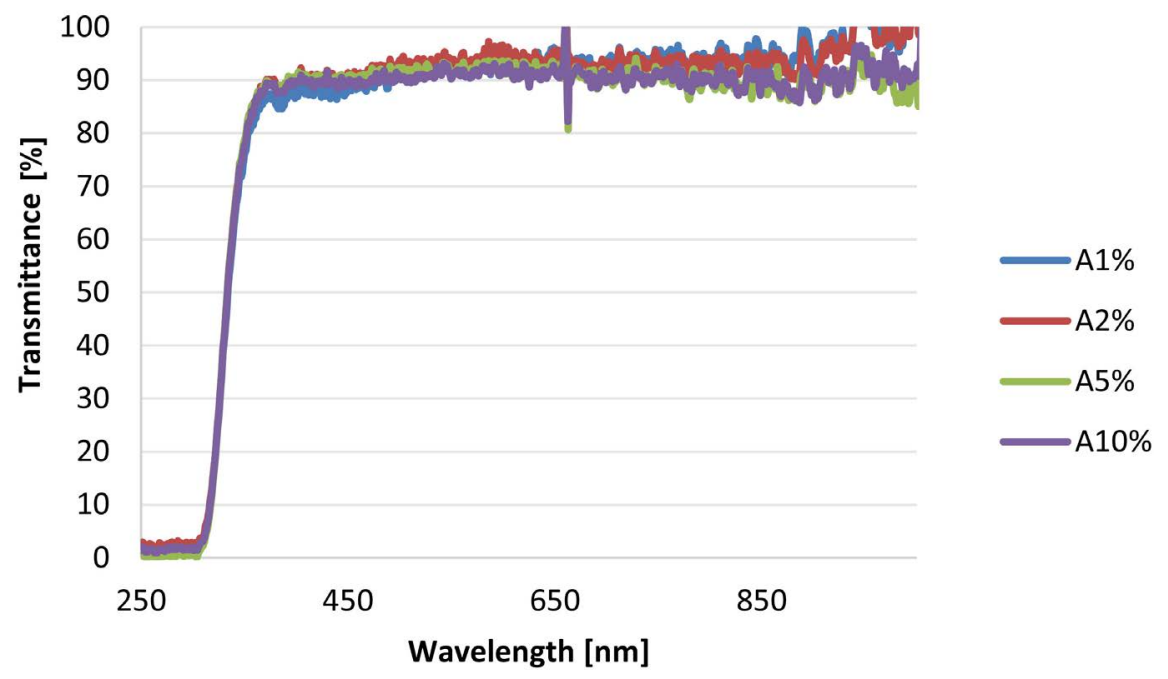

Figure 8. The transmittance corresponding to category A with $1 \%, 2 \%, 5 \%$ and $10 \%$ of glass balls.

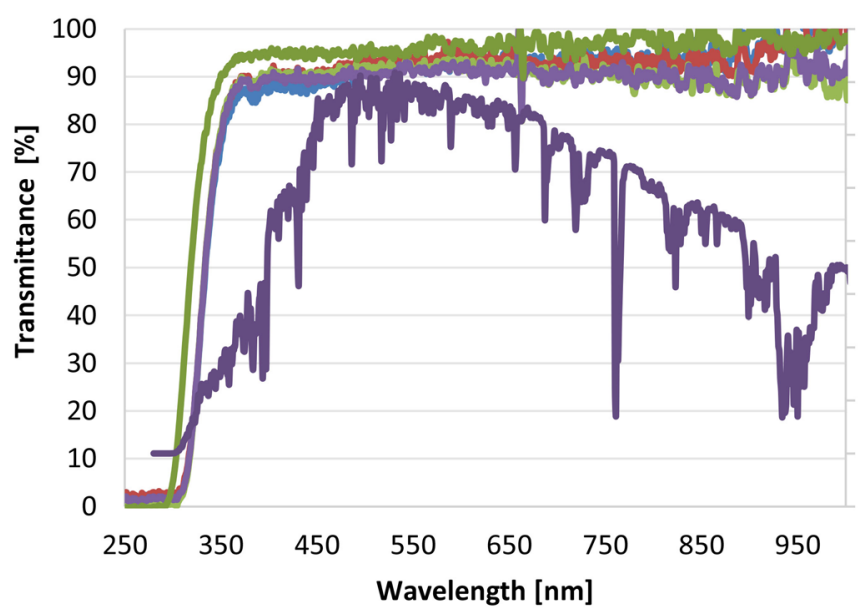

$1.6000 \mathrm{E}+00$

$1.4000 \mathrm{E}+00$

$1.2000 \mathrm{E}+00$

$1.0000 \mathrm{E}+00 \longrightarrow \mathrm{A} 1 \%$

8.0000E-01 A2\%

$6.0000 E-01 \longrightarrow A 5 \%$

4.0000E-01 A10\%

2.0000E-01 Silicone

$0.0000 \mathrm{E}+00 \longrightarrow$ Solar spectrum

$-2.0000 \mathrm{E}-01$

Figure 9. Comparison between the transmittance of the samples with glass balls (A) and the samples with only silicone with the consideration of the irradiance.

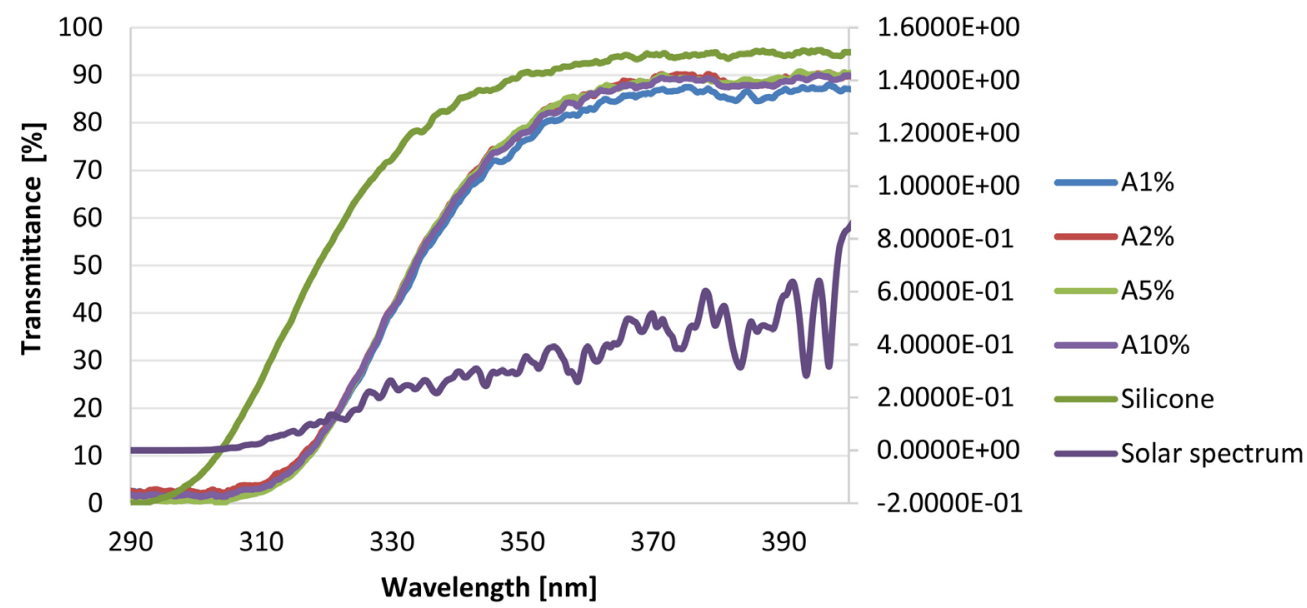

Figure 10. Wavelength interval giving sensitive transmission difference (with glass balls (A) and with only silicone). 


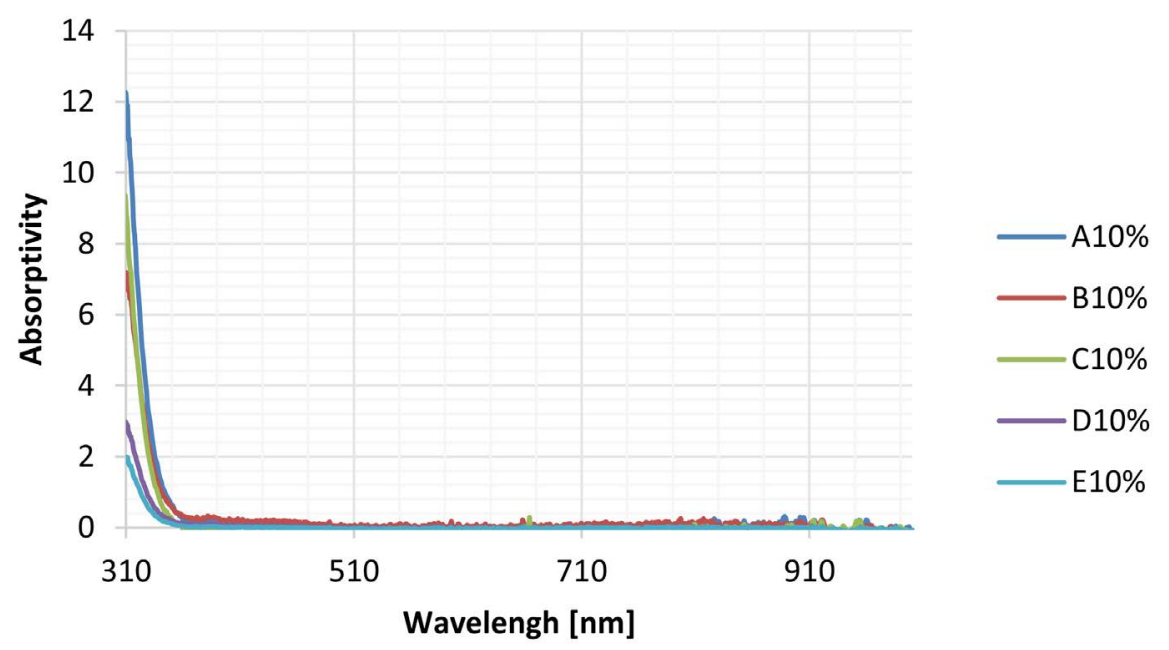

Figure 11. Absorptivity of the samples with different glass balls (A), (B), (C), (D) and (E)

\section{- Absorptivity measurements}

Figure 11 shows that the absorptivity of the samples with different glass balls is almost similar when wave length is above $360 \mathrm{~nm}$, with a feeble value of the order of 0.05 .

A difference is marked for the wavelengths corresponding to the ultra violet (less than $0.4 \mu \mathrm{m}$ ) where the solar irradiation is the lowest especially between (A), (B), (C) categories on one hand and (D) and (E) on the other hand.

\section{Conclusions}

In this work a new adhesive situated between solar cell and secondary optical elements has been manufactured. This adhesive is identified to silicone and transparent glass mixtures. These mixtures are in different mass proportions of the two compounds and they are classified to five categories according to ball sizes parameter. The experimental study of this adhesive for the different categories shows up essentially that the thickness criterion presents the only parameter allowing to the optimal category choice which is the A category (ball sizes $<106$ $\mu \mathrm{m})$. In fact:

- The adhesive minimum thickness value necessary to act as mechanical bond corresponds to A category where the glass balls size is lowest.

- The transmittance is practically the same for the different categories of the order of 0.9 .

- The same thing for the parameter of absortivity is sensibly the same for the different categories of the order of 0.05 .

In the continuity of this work we plan to accomplish the experimental part outside the laboratory directly against solar radiation and then compare the results with those found within the laboratory.

As perspectives this study can be extended to look for other mixtures which improve more mechanical cohesion between the secondary optical elements and the solar cell and at the same time keeping a high transmittance of solar irradiations. 


\section{Acknowledgements}

This work has been carried out for two months at the Solar Energy Institute. The authors acknowledge to this Institute for its invitation and like to thank Dr. Ignacio Antón Hernández and Ms. Marta Victoria Pérez for their support and discussions. Finally, I express thanks to my research laboratory: Energy, Water, Environnemt and Process Analysis for giving me the opportunity to do this internship and I acknowledge the financial support by the University of Gabes.

\section{Conflicts of Interest}

The authors declare no conflicts of interest regarding the publication of this paper.

\section{References}

[1] Kalogirou, S.A. (2014) Solar Energy Engineering: Processes and Systems. 2nd Edition, Academic Press, Millbrae, CA.

[2] Kali, K., Islam, M., Yasmin, M., Das, S. and Sharker, K. (2019) Computational Water, Energy, and Environmental Engineering, 8, 91-98. https://doi.org/10.4236/cweee.2019.84006

[3] Chen, Y.-C. and Chiang, H.-W. (2015) Applied Science, 5, 770-786. https://doi.org/10.3390/app5040770

[4] Luque, A. and Hegedus, S. (2011) Handbook of Photovoltaic Science and Engineering. 2nd Edition, John Wiley \& Sons, United Kingdom. https://doi.org/10.1002/9780470974704

[5] Luque, A. and Andreev, V. (2007) Concentrator Photovoltaic. Springer Verlag, Berlin. https://doi.org/10.1007/978-3-540-68798-6

[6] Andreev, V.M., Grilikhes, V.A., Soluyanov, A.A., Vlasova, E.V. and Shvarts, M.Z. (2008) Optimization of the Secondary Optics for Photovoltaic Units with Fresnel lenses. Proceedings of the 23 th European Photovoltaic Solar Energy Conference, Valencia, 1-5 September 2008, 126-131.

[7] Victoria, M., Domınguez, C., Anton, I. and Sala, G. (2009) Optics Express, 17, 64876492. https://doi.org/10.1364/OE.17.006487

[8] Wiesenfarth, M., Dörsam, T., Eltermann, F., Hornung, T., Siefer, G., Steiner, M., van Riesen, S., Neubauer, M., Boos, A., Wanka, S., Gombert, A. and Bett, A.W. (2015) CPV Module with Fresnel Lens Primary Optics and Homogenizing Secondary Optics. 11 th International Conference on Concentrator Photovoltaic Systems, AIP Conference Proceedings, Volume 1679, Issue 1. https://doi.org/10.1063/1.4931554

[9] Victoria, M., Askins, S., Domınguez, C., Anton, I. and Sala, G. (2013) Solar Energy Materials \& Solar Cells, 113, 31-36. https://doi.org/10.1016/j.solmat.2013.01.039

[10] Han, X. Y., Guo, Y.J., Wang, Q. and Phelan, P. (2018) Solar Energy Materials \& Solar Cells, 174, 124-131 